\title{
ADA Title I allegations and the Mining, Quarrying, and Oil/Gas Extraction industry
}

\author{
Todd A. Van Wieren ${ }^{\mathrm{a}, *}$, Laura Rhoades ${ }^{\mathrm{b}}$ and Brian T. McMahon ${ }^{\mathrm{c}}$ \\ ${ }^{a}$ Department for Disability Access and Advising, Indiana University of Pennsylvania, Indiana, PA, USA \\ ${ }^{\mathrm{b}}$ Department of Safety Sciences, Indiana University of Pennsylvania, Indiana, PA, USA \\ ${ }^{\mathrm{c}}$ Department of Rehabilitation Counseling, Virginia Commonwealth University, Richmond, VA, USA
}

Received 4 August 2016

Accepted 27 March 2017

\begin{abstract}
.
BACKGROUND: The majority of research about employment discrimination in the U.S. Mining, Quarrying, and Oil/Gas (MQOGE) industries has concentrated on gender and race, while little attention has focused on disability.

OBJECTIVE: To explore allegations of Americans with Disabilities Act (ADA) Title I discrimination made to the Equal Employment Opportunity Commission (EEOC) by individuals with disabilities against MQOGE employers.

METHODS: Key data available to this study included demographic characteristics of charging parties, size of employers, types of allegations, and case outcomes. Using descriptive analysis, allegation profiles were developed for MQOGE's three main sectors (i.e., Oil/Gas Extraction, Mining except Oil/Gas, and Support Activities). These three profiles where then comparatively analyzed. Lastly, regression analysis explored whether some of the available data could partially predict MQOGE case outcomes.

RESULTS: The predominant characteristics of MQOGE allegations were found to be quite similar to the allegation profile of U.S. private-sector industry as a whole, and fairly representative of MQOGE's workforce demographics. Significant differences between MQOGE's three main sector profiles were noted on some important characteristics. Lastly, it was found that MQOGE case outcomes could be partially predicted via some of the available variables.
\end{abstract}

CONCLUSIONS: The study's limitations were presented and recommendations were offered for further research.

Keywords: Employment discrimination, private-sector industry, disability, Equal Employment Opportunity Commission (EEOC)

\section{Introduction}

Mining, the extraction of non-renewable resources from the earth, is an ancient occupation dating back to prehistoric times [1-3]. Evidence exists of ancient mining activities including archeological sites in both the North and South American continents [4, 5]. In the more recent history of the U.S., mining has become a part of our national, cultural narrative (e.g., the

\footnotetext{
*Address for correspondence: Todd A. Van Wieren, Department for Disability Access and Advising, Indiana University of Pennsylvania, Indiana, PA, USA. Tel.: +1 724357 4067; Fax: +1 724357 2889; E-mail: toddvw@iup.edu.
}

Western Gold Rush, Appalachian coal mining, and the Texas Oil Boom). In the late 1990s, a "Shale Gas Boom" occurred in the U.S. when a technological breakthrough allowed for the combination of hydraulic fracking with horizontal drilling. This resulted in a doubling of the oil/gas industry workforce from 2003 - 2013. This period included an unprecedented increase in the production of natural gas [6-8].

As of 2014, the Mining, Quarrying, and Oil/Gas Extraction (MQOGE) industries employed approximately 843,800 individuals in the U.S. It is projected that by 2024 , there will be 924,000 workers in MQOGE industries [9]. 
Corporations operating within MQOGE industries, like most U.S. employers, must maintain non-discriminatory workplace practices related to characteristics of race, color, religion, sex, national origin, age, genetic information, and disability. Title I of the Americans with Disabilities Act (ADA) is a major federal law designed to protect workers with disabilities from discrimination in employment. The Equal Employment Opportunity Commission (EEOC) is the federal agency that is tasked with enforcing Title I of the ADA. The EEOC investigates allegations of workplace discrimination, determines whether or not discrimination actually occurred, and attempts to resolve charges in various manners depending on the circumstances.

Aside from the field of Safety Sciences, which has focused on reducing work-related injury and illness, little research attention has been paid to disability within MQOGE industries, and none exists on the more specific topic of disability discrimination.

\section{Background: MQOGE industry}

\subsection{MQOGE sectors and employment data}

The North American Industry Classification System (NAICS), utilized by the U.S. Bureau of Labor Statistics (BLS), divides MQOGE industries into three main sectors: (1) Oil/Gas Extraction, (2) Mining (except Oil/Gas), and (3) Support Activities for Mining.

The Oil/Gas Extraction sector includes the mining, extraction, and production of crude petroleum, oil from shale and oil sands, natural gas, sulfur recovery from natural gas, and hydrocarbon liquids recovery [10]. As of 2014, this sector employed approximately 197,900 individuals, over $23 \%$ of MQOGE industries [11].

The Mining (except Oil/Gas) sector includes the mining, extraction, and production of coal, metal ore and nonmetallic minerals, and quarrying [12]. As of 2014 , this sector employed approximately 207,400 individuals, almost $25 \%$ of MQOGE industries [9]. Geographically, this sector operates throughout most of the U.S. when considering all commodities (especially sand/gravel, and to a lesser extent stone). Coal production employs the largest number of workers within the sector (33\%) followed by stone production (26\%) [13].

The Support Activities for Mining sector offers wide-ranging services for the other two sectors, such as site preparation and construction, exploration and prospecting, surveying and mapping, and other similar services [14]. In 2014, this sector employed approximately 438,500 individuals, almost $52 \%$ of MQOGE industries [9].

\subsection{MQOGE and disability}

MQOGE industries and many of its jobs are considered "high-risk" for occupational injury/illness and fatality [15]. The work is inherently dangerous and requires extreme physical exertion. Cases of post-employment disability are often associated with work-related injury. Indeed, in a 1993 law review article from the early days of the ADA, the authors speculated that,

"The majority of ADA claims and requests for accommodation in the coal industry will probably occur as a result of employees who have been disabled due to work-related injuries and are seeking to return to work" [16, p. 9].

Coal mining workers in particular are more likely to experience occupational fatality or injury/illness. Furthermore, non-fatal injuries are far more likely to be considered "severe" relative to work-related injuries in private-sector industry as a whole [17]. Serious accidents include explosions, fires, and collapses [18]. Not only is mining dangerous, but the jobs tend to require extreme physical exertion including: repeated lifting and carrying of heavy burdens, withstanding vibrations, bending, twisting of the spine, and prolonged standing [19]. Injuries of the back are the most common, followed by knees, fingers, and shoulders [20]. The mining industry is unique in that work injuries are overseen federally by the specialized Mine Safety and Health Administration (MSHA), not the Occupational Safety and Health Administration (OSHA). Fortunately, MSHA reports that occupational fatalities and injuries in the mining industry consistently decline over time, with a recent record low injury rate in 2014 of 2.43 injuries per 200,000 hours worked [21, 22]. Recent advances in mining technology include better dust ventilation systems and automated machines that contribute to improved worker safety and health [23].

Occupations within the Oil/Gas Extraction industry are also considered relatively dangerous. For example, OSHA recently issued a revised Regional Emphasis Program (REP) to focus inspections in the Oil/Gas Extraction industry for Region III (where much of the U.S. natural gas production occurs). 
OSHA's goal for the REP is "... to reduce the rate of injuries, illnesses and fatalities ... and to address health hazards as they occur during hydraulic fracturing operations" $[24$, p. 1]. OSHA describes the Oil/Gas Extraction industry as particularly hazardous because it is:

“... an extremely mobile industry with worksites or locations changing on a daily basis. Worksites may remain at one location for a week to two years while others may move to a new location daily. This industry involves working with heavy equipment, such as drilling rigs and associated oil field equipment; working with high pressure $\mathrm{Oil} / \mathrm{Gas}$ systems; working in hazardous locations containing explosive concentration of hydrocarbons and high exposure levels to hydrogen sulfide; working at elevated work stations; and working with heavy power equipment. Other hazards associated with this industry include, but are not limited to, exposure to high voltage, chemical injury to the eyes and face, fires and explosions." [24, p. 4-5]

\subsection{MQOGE workplace inclusion and discrimination}

The majority of MQOGE research on protected classes has focused to date on gender and race. It is well known that the MQOGE workforce has long been dominated by white males [25], and has faced problems in the past with discrimination toward non-white and female individuals, holding a reputation as a "macho industry" [26]. It has also been described as "non-engaging" of LGBT concerns for its employees [27]. Historically, female employment opportunities in the Oil/Gas Extraction industry have mostly been limited to lower-paying supplemental jobs with a smattering of higher-paying engineering or non-production jobs. Access is limited to the vast majority of the industry's jobs which are midlevel and labor-intensive [28]. After a 1978 lawsuit, coal mining became an industry targeted for affirmative action efforts, and more female employees were hired. Yet these female workers often found it difficult to gain access to equitable opportunities for promotion to more highly-skilled and better-paying jobs [29].

Overall, MQOGE industries are among the least diverse in U.S. private-sector industry [25]. According to 2015 labor force statistics from the Current Population Survey, MQOGE employed $13 \%$ females vs. $47 \%$ nationally, and $24 \%$ racial/ethnic minorities vs. 34\% nationally. Of the MQOGE sub-sectors, the Coal Mining workforce is notably populated by white males, with only $5 \%$ female and $2 \%$ racial/ethnic minorities [30]. The MQOGE industry's bias may be changing slowly as it becomes apparent that recruiting and hiring more female and minority employees will be crucial to meet future workforce demands [25, $28,31]$.

\subsection{The National EEOC ADA Research Project (NEARP)}

The data for this study were taken from the ADA Title I portion of the EEOC's Integrated Mission System (IMS), initially obtained in 2003 by the National EEOC ADA Research Project (NEARP) through an interagency personnel agreement. The IMS is used by the EEOC as a management tool for tracking its field investigations from case inception through outcome and closure. NEARP is an informal consortium of over 75 researchers who have published more than 70 journal articles to date using the ADA Title I IMS dataset [32]. Many of these published studies have focused on a specific type of disability, including two involving the present authors with respect to autism [33, 34]. Only one published NEARP study to date has focused on a particular industry; i.e., healthcare [35]. In that study, the researchers found that information regarding the specific healthcare sector and the race of charging parties (i.e., persons who have filed charges of discrimination with the EEOC) could be used to predict the outcome of investigations.

Other NEARP studies detected findings related to the MQOGE industry. For example, discrimination was less frequently alleged in MQOGE by charging parties with multiple sclerosis or cumulative trauma disorders [36, 37]. MQOGE experienced lower levels of charges when the type of allegation involved disability harassment [38]. Finally, persons whose charges involved being regarded as disabled prevailed more often in establishing merit (i.e., actual discrimination) of their charge when it was against a MQOGE employer [39].

\section{Project design and methods}

\subsection{Study dataset and variables}

From the NEARP dataset, which holds 547,866 allegations, a smaller dataset was extracted for this 
study to include only those cases and variables related to the research questions and to maximize consistency, parsimony, and confidentiality. The extraction process was guided by the following considerations: The unit of study is an allegation; it is not an individual charging party (i.e., person who has filed a charge of discrimination with the EEOC) or an individual employer, because a single charging party may bring more than one allegation to the EEOC in the same complaint or over time. Only unique allegations that do not involve recording errors or duplications were included in the study dataset. All identifying information regarding charging parties and employers was purged except variables important for this research. Study data were strictly limited to allegations brought under Title I of the ADA; allegations brought under other federal employment statutes were not considered. State-investigated allegations were also excluded to maintain a consistent definition of both disability and discrimination. To maintain consistency in definitions and procedures among the study variables, only allegations received, investigated, and closed by the EEOC were included. This required the exclusion of allegations referred by the EEOC to litigation for disposition in civil state or federal courts. Allegations of retaliation were excluded because complaints of this nature do not pertain directly to the existence or consequence of disability. Only allegations that were closed by the EEOC during the study period (defined as July 26, 1992 [first effective date of the ADA] through December 31,2011 ) were included in the study dataset. Finally, open allegations (still under investigation as of December 31, 2011) were excluded from the study. This exclusion exists to ensure that all allegations in the study dataset are closed, and as such are known to be either with merit (decided by the EEOC to have reasonable cause for discrimination) or non-merit (decided by the EEOC to have no reasonable cause for discrimination).

The resulting study dataset included 3,236 allegations of ADA Title I employment discrimination against employers in the MQOGE industry, which were received, investigated, and closed by the EEOC during the study period. These 3,236 allegations were divided into three groups on the basis of the industry's three main sectors: Oil/Gas Extraction (994 allegations), Mining except Oil/Gas (1,292 allegations), and Support Activities for Mining (950 allegations).

The following contextual information for each allegation was available and used for this study: (a) charging party demographics, including age, gender, race, and disability (42 disability types broken down into 5 general categories); (b) employer characteristics, including size (four size categories) and MQOGE sector (three main industry categories); (c) the type of ADA Title I allegation (23 allegation types broken down into 6 general categories), and (d) the EEOC outcome of the investigation (thirteen outcome types broken down into two categories; i.e., merit or non-merit).

\subsection{Research objectives and data analysis}

Using SPSS (Statistical Package for the Social Sciences), data were analyzed to answer the study's three research objectives:

The first research objective for this study was descriptive in nature and focused on examining the most prevalent characteristics associated with the MQOGE industry's three main sectors. Percentages and mean averages of the variables were used to describe industry characteristics in order to arrive at a "typical profile" of a MQOGE allegation.

The second research objective was comparative in nature and explored whether the characteristics associated with the three main MQOGE sector allegations differ from each other. One-way ANOVA and two-way contingency tables (depending on the level of measurement of the different variables) were used to analyze the data. For any variables that were found to be significant for one of the three MQOGE sectors, odds ratios were then calculated to determine the likelihood of that characteristic occurring in the particular MQOGE sector vs. the other two.

The third research objective of this study, predictive in nature, explored whether the final EEOC case resolutions (i.e., merit vs. non-merit) for MQOGE industries could be predicted based upon a function of some of the contextual variables available in the dataset. Forward, stepwise multiple logistic regression analysis was used to establish a model that contained the best set of predictor/coefficient variables which could differentiate the dependent variable of merit vs. non-merit outcome. The statistical significance of each of the model's coefficients was evaluated using the Wald test. The selection of the predictor variables for the final model progressed via steps while the different predictor variables were either included or excluded from the model, in an attempt to realize the largest increase in the $\mathrm{R}$-squared measure of predictive power. 
Table 1

Descriptive and comparative analysis for MQOGE Sectors

\begin{tabular}{|c|c|c|c|}
\hline & Oil/Gas \% & Mining \% & Support Activities $\%$ \\
\hline $\begin{array}{l}\text { CHARGING PARTY DISABILITY } \\
\text { - Physical } \\
\text { - Other Definition of Disability } \\
\text { - Other Physical or Behavioral } \\
\text { - Behavioral (Chem. Dep./Psych) } \\
\text { - Neurological } \\
\text { - Sensory }\end{array}$ & $\begin{array}{l}38 \% \\
19 \% \\
17 \% \\
16 \% \\
8 \% \\
4 \%\end{array}$ & $\begin{array}{l}39 \% \\
18 \% \\
16 \% \\
13 \% \\
8 \% \\
5 \%\end{array}$ & $\begin{array}{l}39 \% \\
14 \% \\
18 \% \\
13 \% \\
12 \% * * \\
4 \%\end{array}$ \\
\hline $\begin{array}{l}\text { CHARGING PARTY AGE } \\
\text { - Age (mean years of Age) }\end{array}$ & 45 & 45 & 45 \\
\hline $\begin{array}{l}\text { CHARGING PARTY RACE } \\
\text { - White } \\
\text { - African American } \\
\text { - Hispanic/Mexican American } \\
\text { - Other Race } \\
\text { - Native American } \\
\text { - Asian American } \\
\text { - Mixed }\end{array}$ & $\begin{array}{l}61 \% \\
21 \%^{* *} \\
8 \% \\
8 \% * * \\
1 \% \\
1 \% \\
1 \%\end{array}$ & $\begin{array}{l}70 \% \\
12 \% \\
12 \% \\
4 \% \\
2 \% \\
0 \% \\
0 \%\end{array}$ & $\begin{array}{l}71 \% \\
13 \% \\
7 \% \\
6 \% \\
1 \% \\
2 \% * * \\
0 \%\end{array}$ \\
\hline $\begin{array}{l}\text { CHARGING PARTY GENGER } \\
\text { - Male } \\
\text { - Female }\end{array}$ & $\begin{array}{l}73 \% \\
27 \%\end{array}$ & $\begin{array}{l}78 \% * * \\
22 \%\end{array}$ & $\begin{array}{l}72 \% \\
29 \%\end{array}$ \\
\hline $\begin{array}{l}\text { EMPLOYER SIZE } \\
-15-100 \text { employees } \\
-101-200 \text { employees } \\
-201-500 \text { employees } \\
-501+\text { employees }\end{array}$ & $\begin{array}{l}28 \% \\
10 \% \\
11 \% \\
51 \%\end{array}$ & $\begin{array}{l}34 \% * \\
14 \% * \\
13 \% * \\
39 \%\end{array}$ & $\begin{array}{c}28 \% \\
7 \% \\
11 \% \\
54 \%\end{array}$ \\
\hline $\begin{array}{l}\text { ALLEGATIONS } \\
\text { - Job Acquisition } \\
\text { - Quality of Work } \\
\text { - Job Retention } \\
\text { - Other/Miscellaneous }\end{array}$ & $\begin{array}{c}7 \% \\
44 \% \\
45 \% \\
5 \%\end{array}$ & $\begin{array}{c}8 \% \\
43 \% \\
46 \% \\
2 \%\end{array}$ & $\begin{array}{c}6 \% \\
44 \% \\
45 \% \\
5 \%\end{array}$ \\
\hline $\begin{array}{l}\text { OUTCOMES } \\
\text { - Merit } \\
\text { - Non-Merit }\end{array}$ & $\begin{array}{l}25 \% \\
76 \%\end{array}$ & $\begin{array}{l}23 \% \\
77 \%\end{array}$ & $\begin{array}{l}30 \% \text { ** } \\
71 \%\end{array}$ \\
\hline
\end{tabular}

*More likely - significant at 0.01 level. ${ }^{* *}$ More likely - significant at 0.001 level.

\section{Results}

\subsection{Descriptive analysis}

Based upon the descriptive analysis portion of this study, it could be said that the profile for a typical MQOGE industry allegation entails: (a) a charging party who is 45 years old, white, male, and has a physical disability (back impairment most prevalent at $16 \%$ of all MQOGE allegations); (b) an employee workforce either in the smallest size category (15100 employees) or the largest category (501+); (c) an allegation from the "quality of work" category (failure of "reasonable accommodation" being the highest type at $16 \%$ ) or the "job retention" category ("discharge" being the highest type at 34\%); and (d) an investigation outcome that the EEOC determined to be non-meritorious. See Table 1 for a more detailed account of the descriptive analysis portion of this study.

\subsection{Comparative analysis}

The one-way ANOVA and two-way contingency table analysis, used to determine if there were differences in the types of allegations made with regard to the three main MQOGE sectors, revealed significance in a few characteristics. Relative to the other sectors, the Oil/Gas Extraction sector allegations were almost twice as likely to be made by African American charging parties $\left[\chi^{2}(1, \mathrm{~N}=3068)=34.413\right.$, $p<0.000]$ and almost twice as likely by "other race" charging parties $\left[\chi^{2}(1, N=3068)=10.694\right.$, $p=0.001]$. For the Mining (except Oil/Gas) sector, 
allegations were almost one-and-a-half times more likely to be made by male charging parties $\left[\chi^{2}(1\right.$, $\mathrm{N}=3215)=14.812, p=0.004]$, and more likely to be made against small to medium-sized category employers (15-100, 101-200, and 201-500 employees categories) $[F(9,3109)=21.65, p<0.000]$. Finally, for the Support Activities for Mining sector, allegations were over 4 times more likely to be made by Asian American charging parties $\left[\chi^{2}(1\right.$, $\mathrm{N}=3068)=17.945, p<0.000]$ and one-and-a-half times more likely by charging parties with neurological category disabilities $\left[\chi^{2}(1, \mathrm{~N}=3236)=8.502\right.$, $p=0.004]$. Support Activities sector allegations were also one-and-a-half times more likely to receive merit outcomes $\left[\chi^{2}(1, \mathrm{~N}=3236)=12.533, p<0.000\right]$. This means that substantially more "actual discrimination" (vs. perceived discrimination) was determined by the EEOC to have been detected in the Support Activities sector. See Table 1 for further details.

\subsection{Predictive analysis}

Forward, stepwise, multiple logistic regression analysis revealed that charging party race (white), charging party disability category (behavioral), MQOGE sector (Support Activities for Mining), and allegation categories ("job acquisition" and "other/miscellaneous") contributed the most to the explanatory power of the model $(\chi 2=128.760$, $p=<0.000, \mathrm{df}=5)$. These variables accounted for approximately $4 \%$ to $6 \%$ of the variance in merit vs. non-merit outcomes (i.e., Cox \& Snell R2 $=0.041$, Nagelkerke R2=0.061). The results of the final model are detailed in Table 2. The effect size of the model may be relatively small. However, many other factors, not available for analysis in this study, would presumably add to the prediction of EEOC case outcomes, and therefore a small effect size in this instance can still present some scientific significance [40].

Based on this model, the odds of merit outcomes for MQOGE industry allegations tend to increase when they entail: (a) charging parties with behavioral category disabilities (over one-and-a-half times more likely, $\operatorname{Exp}[\beta]=1.686$ ), (b) "job acquisition" category allegations (almost two-and-a-half times more likely, $\operatorname{Exp}[3]=2.347$ ), and/or "other/miscellaneous" category allegations (almost 3 times more likely, $\operatorname{Exp}[3]=2.894$ ). However, the odds of merit outcomes tend to decrease when MQOGE allegations entail: (a) charging parties who are white (over one-and-a-half times less likely, $\operatorname{Exp}[\beta]=0.563$ ) and (b) employers from the Support Activities for Mining sector (over one-and-a-half times less likely, $\operatorname{Exp}[\beta]=0.740$ ).

\section{Discussion}

\subsection{MQOGE allegations similar to private industry allegations as a whole}

One of the more prominent findings of this study, which emerged from the descriptive analysis, is that the typical MQOGE industry allegation characteristics are very similar overall to what we know from the NEARP data about the most frequent characteristics of allegations for private-sector industry as a whole $[32,41]$. These similarities are found for all of the contextual variables that were available to this study, except for gender. The typical allegation profile shared by both MGOGE and private-sector industry as a whole include: (a) charging party median age of 45 years, (b) charging party race of white ethnicity, (c) charging party disability from the physical category (back impairment in particular), (d) employer size from either the smallest (15-100 employees) or the largest categories (501+ employees), (e) types of allegations from either the "quality of work" category ("reasonable accommodation" in particular) or the "job retention" category ("discharge" in particular), and (f) approximately one-fourth of case outcomes determined by the EEOC as meritorious.

Table 2

Final model for logistic regression analysis of MQOGE Industry Merit vs. Non-Merit Outcomes

\begin{tabular}{lccccccc}
\hline Predictor & \multicolumn{1}{c}{ SE } & Wald & $d f$ & $p$ & $\operatorname{Exp}(\beta)$ for $\operatorname{Exp}(\beta)$ & $95 \%$ C.I. \\
\hline - Race (White) & -0.574 & 0.096 & 35.371 & 1 & 0.000 & 0.563 & $0.466-0.681$ \\
- Disability (Behavioral) & 0.522 & 0.139 & 14.202 & 1 & 0.000 & 1.686 & $1.285-2.211$ \\
- Sector (Support Activities) & -0.301 & 0.090 & 11.173 & 1 & 0.001 & 0.740 & $0.620-0.883$ \\
- Allegation (Job Acquisition) & 0.853 & 0.146 & 34.051 & 1 & 0.000 & 2.347 & $1.762-3.126$ \\
- Allegation (Miscellaneous) & 1.063 & 0.190 & 31.362 & 1 & 0.000 & 2.894 & $1.995-4.198$ \\
- Constant & -1.282 & 0.146 & 77.489 & 1 & 0.000 & & \\
\hline
\end{tabular}

Model Summary: $\mathrm{N}=3236, \mathrm{df}=5, \chi 2=128.760, p=0.000, \mathrm{R} 2=0.041$ (Cox \& Snell), 0.061 (Nagelkerke). 


\subsection{MQOGE allegations consistent with industry workforce demographics}

Another interesting finding from this study, again from the descriptive analysis, is that the MQOGE allegation profile is quite representative of what we know about some of the important demographic characteristics of the industry's workforce. This can be seen in the areas of employee age, gender, race, and possibly in the industry's relatively higher risk for work injury/disability.

A median age of 45 years for the allegations' responding parties is fairly similar to the active MQOGE industry's workforce, depending on the subsector. For instance, the Oil/Gas Extraction and the Support Activities for Mining workforces have the youngest median ages at 40 years, followed by Coal Mining at 43 years, and Mineral Mining/Quarrying at 46 years [30].

As formerly noted, the MQOGE workforce is overwhelmingly male. As would then be expected, this study found that the highest number of allegations have also come from males. This is quite different from the male/female proportions for all privatesector industry allegations as a whole, which are evenly split [32].

Furthermore, as discussed previously, the MQOGE workforce is much less racially diverse than most other private-sector industries in the U.S. Consistent with this, the highest proportion of allegations from this industry are from white charging parties.

Lastly, as speculated earlier in this paper, that cases of disability amongst workers in MQOGE industries might have a relatively higher risk of being linked to work-related injury, it could then be expected that disabilities of a physical nature would be the most prevalent allegations of discrimination (e.g., injuries to backs, knees, fingers, shoulders, disfigurement due to burns, etc.). Indeed, the most common allegations from MQOGE industries involve physical category disabilities (back impairments the most predominant type from this category). This is only speculation though, as a limitation of this study's dataset is that it is impossible to tell whether the disabilities associated with the allegation cases are pre-existing, work-related, non-work-related, etc.

\subsection{Allegation characteristics of concern for MQOGE's three main sectors}

The comparative analysis portion of this study revealed a few differences amongst the allegation profiles of MQOGE's three main sectors. These differences represent areas of unique concern that should be considered by employers within each of these respective sectors.

The Oil/Gas Extraction allegations were more likely (relative to the other two sectors) to be made by African Americans and "other race" individuals. A possible reason for this might involve the fairly recent Shale Gas Boom over the past decade, as well as the higher proportion of non-white employees in the Oil/Gas Extraction sector (22\% racial/ethnic minorities), relative to the Mining except Oil/Gas sector (2\% for Coal Mining; $15 \%$ for Mineral Mining/Quarrying). The Oil/Gas Extraction sector grew its workforce very quickly over a short period of time (as well as the Support Activities for Mining sector in tandem with the needs of the booming oil/gas production industry). Meanwhile, proportionally more minority employees were hired (relative to Mining except Oil/Gas). Perhaps the employers' human resources protocol and expertise may not have kept pace with their fast, increasing workplace diversity.

The Mining (except Oil/Gas) sector allegations were more likely to be made by male charging parties, and against small-to-medium sized category employers. Proportionally higher allegations from males in this sector might be expected since one of the primary sub-sectors within Mining (except Oil/Gas) is Coal Mining, which has an especially high proportion of male employees ( $95 \%$ male vs. only $5 \%$ female). Of unique interest for the Mining (except Oil/Gas) sector as well is that employers with less than 500 employees (i.e., those that fall within the small-to-medium sized categories) seem to be particularly exposed to the risk of allegations.

The Support Activities for Mining allegations were more likely to be made by Asian Americans and by individuals from the neurological disability category. This sector's allegations were also more likely to result in a merit outcome. Considering the issue of race, the Support Activities sector has more nonwhite employees (28\% racial/ethnic minorities) than the other two. The elevated Asian American allegation proportion might be linked to the Shale Gas Boom because the Support Activities sector grew in tandem with the needs of the booming oil/gas production industry. The reason for the Support Activities sector's higher proportion of neurological disability category allegations is not obvious, but two specific impairments that fall under the neurological category of disability include brain/head injury and cumulative 
trauma disorder. These impairments may be associated with work-related injury. The reason for the Support Activities sector's higher proportion of merit outcomes is also not immediately evident because this sector is somewhat less defined than the other two.

\subsection{Considering MQOGE allegation outcomes}

Allegation outcomes are an especially important issue of this study to consider. In the case of meritorious outcomes, the EEOC has determined that circumstances or information exist to reasonably conclude that employment discrimination has actually occurred against individuals with disabilities. This is not to say that discrimination did not occur in the non-merit outcome cases, but rather only that the circumstances or information for these cases did not allow the EEOC to definitively conclude that discrimination occurred. It would be especially vital for MQOGE employers and future researchers to consider the findings around allegation characteristics in which the EEOC has concluded that discrimination actually occurred.

First, as mentioned in earlier sections of this discussion, approximately one-fourth of MQOGE case outcomes are ruled as meritorious by the EEOC (similar to the rate of merit outcomes for private-industry allegations as a whole) and allegations from the Support Activities of Mining sector tend to result in a higher proportion of merit outcome (relative to MQOGE's other two main sectors).

Second, the predictive analysis portion of this study found, in part, that the odds of a merit outcome for MQOGE allegations tend to increase when they entail charging parties with behavioral category disabilities, "job acquisition" category allegations, and "other/miscellaneous" category allegations. The issue of behavioral category disability allegations as a partial predictor for merit outcomes is interesting because while it is known that society's negative attitudes tend to be more predominant against persons with behavioral disabilities [32, 41], past NEARP studies have revealed that, for all allegations in private-sector industry as a whole, merit outcomes are higher for physical or sensory category disabilities [42]. Interacting in a legally appropriate manner with employees who have behavioral category disabilities (such as mental health impairments or alcohol/substance addictions) may be a matter that MQOGE industries should uniquely focus on. Furthermore, perhaps the industry might pursue solutions using the Drug Free Workplace Act, which could help to mitigate many ADA Title I complaints involving chemical dependency in the workforce. Lastly, the finding that allegations from the "job acquisition" category were partially predictive of merit outcome was interesting as well. Allegations related to hiring are within the "job acquisition" category and are one of the five most prominent specific types of allegation for the private-sector industry as a whole. Furthermore, for private-sector industry as a whole, hiring allegations tend to result in merit outcomes more than the other predominant types of allegations [32, 42].

\section{Conclusions and recommendations}

This study revealed, through the findings of the descriptive analysis, that the typical MQOGE allegation profile is very similar to private-sector industry allegations as a whole, and that the typical MQOGE allegation profile is fairly representative of MQOGE's known workforce demographics. The unique allegation characteristics and concerns for each of MQOGE's three main sectors, utilizing the comparative analysis findings of this study, were then discussed. Lastly, incorporating the predictive analysis findings of this study, the importance of considering what was learned about MQOGE merit outcomes (wherein the EEOC determined that discrimination definitively occurred) were addressed.

The primary limitations of this study were related to the nature of the data. Because this study utilized a secondary data source, the information was not initially gathered for the purpose of research, but rather for the EEOC's administrative needs. Furthermore, in order to protect charging parties' and employers' confidentiality, not all available information from the data source was available for research (for instance, more variables in the dataset could have presumably aided in the logistic multiple regression analysis). One of the most important aspects of these dataset limitations though was that it is impossible to ascertain which allegations involve pre-existing, work-related, or non-work-related disabilities. This is an issue for this study because, as noted previously, the MGOQE industry is known to be particularly high-risk for work-related injuries. It is possible that many of the MQOGE allegations analyzed in this study may have involved disabilities that were related to work injury, but without further data in this regard this cannot be known. This would be a particularly important area for further research, as it could help to 
determine efforts to better prevent and resolve ADA Title I discrimination in the MQOGE industry. For example, if many of the EEOC allegations were actually found to be related to workplace injuries, then better efforts directed towards workplace safety sciences and post-injury vocational rehabilitation and return-to-work efforts might be an appropriate initial focus to help MQOGE industries become a more inclusive workplace environment for employees with disabilities.

Another important area of interest that arose in this study that deserves further research efforts, but which the limitations of this study prevent, is the matter of relatively higher proportions of allegations from minorities in the MQOGE sectors of Oil/Gas Extraction (African Americans and "other races") and Support Activities for Mining (Asian Americans). It would be important to explore whether this problem is related to the recent, rapid growth of these sectors via the Shale Gas Boom, or due to other/additional causes. Furthermore, MQOGE industries have long been dominated by white males and has faced problems in the past with discrimination toward non-whites and females. Further research into how such an industry culture might also affect the inclusion or discrimination of employees with disabilities would be especially valuable for ADA Title I allegation prevention and resolution efforts.

\section{Conflict of interest}

None to report.

\section{References}

[1] Breitenlechner E, Stollner TH, Thomas P, Lutz J, Oeggl K. An interdisciplinary study on the environmental reflection of prehistoric mining activities at the Mitterberg main load (Salsburg, Austria). Archaeometry 2014;56(1):102-28.

[2] Sullivan M, Hughes P, Mosig Way A, Spooner N. Prehistoric mining at olympic dam in arid South Australia. Archaeology in Oceania 2014;49:43-55.

[3] Timberlake S. New investigations and new ideas on Prehistoric-Roman metal mining and smelting in Wales. Mining History: The Bulletin of the Peak District Mines Historical Society 2015;19(3):21-30.

[4] Martin SR. Evidence for indigenous hardrock mining of copper in Ancient North America. Journal of the West 2004;43(1):8-13.

[5] Salazar D, Jackson D, Guendon JL, Salinas H, Morata D, Figueroa V, et al. Early evidence (ca. 12,000 BP) for iron oxide mining on the Pacific Coast of South America. Current Anthropology 2011;52(3):463-75.
[6] Blackley DJ, Retzer KD, Hubler WG, Hill RD, Laney AS. Injury rates on new and old technology oil and gas rigs operated by the largest United States onshore drilling contractor. American Journal of Industrial Medicine 2014;57: 1188-92.

[7] Mason KL, Retzner KD, Hill R, Lincoln JM. Occupational fatalities during the oil and gas boom - United States, 2003-2013. Morbidity and Mortality Weekly Report 2015;64(20):551-4.

[8] Oglend A, Lindback ME, Osmundsen P. Shale gas boom affecting the relationship between LPG and oil prices. The Energy Journal 2015;36(4):265-86.

[9] U.S. Bureau of Labor Statistics. Employment by major industry sector [Internet]. Washington D.C.: U.S. Bureau of Labor Statistics; 2015 [updated 2015 Dec 8; cited 2016 May 30]. Available from: http://www.bls.gov/emp/ep_ table_201.htm

[10] U.S. Bureau of Labor Statistics. Industries at a glance: Oil and gas extraction: NAICS 211 [Internet]. Washington D.C.: U.S. Bureau of Labor Statistics; 2016 [cited 2016 May 30]. Available from: http://www.bls.gov/iag/tgs/iag211.htm

[11] U.S. Energy Information Administration. Gas production in conventional fields, lower 48 states [Internet]. Washington D.C.: U.S. Energy Information Administration; 2009 [updated 2009 April 8; cited 2016 May 31]. Available from: https://www.eia.gov/oil_gas/rpd/conventional_gas.pdf

[12] U.S. Bureau of Labor Statistics. Industries at a glance: Mining (except oil and gas): NAICS 212 [Internet]. Washington D.C.: U.S. Bureau of Labor Statistics; 2016 [cited 2016 May 30]. Available from: http://www.bls.gov/iag/tgs/iag212.htm

[13] National Institute for Occupational Safety and Health. Active mining operations by commodity [Internet]. Atlanta, GA: National Institute for Occupational Safety and Health; 2013 [cited 2016 May 31]. Available from: http://www.cdc. gov/niosh/mining/UserFiles/statistics/13m11aoa_commod. svg

[14] U.S. Bureau of Labor Statistics. Industries at a glance: Support activities for mining: NAICS 213 [Internet]. Washington D.C.: U.S. Bureau of Labor Statistics; 2016 [cited 2016 May 30]. Available from: http://www.bls.gov/iag/ tgs/iag213.htm

[15] Council of State and Territorial Epidemiologists. Occupational health indicators [Internet]. Atlanta, GA: Council of State and Territorial Epidemiologists; 2016 [cited 2016 June 1]. Available from: http://www.cste.org/?OHIndicators

[16] Chetlin SE, Baker ME. Meeting the challenge at the mines: The Americans with Disabilities Act. West Virginia Law Review 1994;96(Spring):1-16.

[17] U.S. Bureau of Labor Statistics. Injuries, illnesses, and fatalities in the coal mining industry [Internet]. Washington D.C.: U.S. Bureau of Labor Statistics; 2010 [updated 2010 April; cited 2016 June 2]. Available from: http://www.bls. gov/iif/oshwc/osh/os/osar0012.htm

[18] Boal WM. The effect of unionism on accidents in U.S. coal mining, 1897-1929. Industrial Relations 2009;48(1): 97-120.

[19] Gianchandani S, Ganvir SS. Prevalence and predisposing factors in low back pain among male underground miners. Indian Journal of Physiotherapy \& Occupational Therapy 2011;5(2):134-7.

[20] National Institute for Occupational Safety \& Health. Mining facts -2014 [Internet]. Atlanta, GA: National Institute for Occupational Safety and Health; 2014 [cited 2016 June 2]. Available from: http://www.cdc.gov/niosh/mining/ works/statistics/factsheets/miningfacts2014.html 
[21] Mine Safety and Health Administration. Mine safety and health at a glance [Internet]. Arlington, VA: Mine Safety and Health Administration; 2015 [updated 2015 July 20; cited 2016 June 3]. Available from: http://arlweb.msha.gov/ MSHAINFO/FactSheets/MSHAFCT10.asp

[22] National Mining Association. Safety statistics [Internet]. Washington D.C.: National Mining Association; 2015 [cited 2016 June 3]. Available from: http://www.nma.org/index. php/safety-statistics

[23] Kenealy B. Coal mining firms strive to clean up image as safety concerns grab regulators attention: Technology advances help keep miners safe underground and on the surface. Business Insurance 2015;49(2): 17.

[24] Occupational Safety \& Health Administration. OSHA regional notice: Directive number 2016-01: Regional emphasis program for the gas and oil service industry [Internet]. Washington D.C.: Occupational Safety \& Health Administration; 2016 [cited 2016 June 3]. Available from: https://www.osha.gov/dep/leps/RegionIII/reg3_fy2016_ Oil_and_Gas_2016-01.pdf

[25] Puko T. Minorities crucial to filling Marcellus shale drilling jobs [Internet]. Pittsburgh, PA: Tribune Review; 2014 [updated 2014 March 10; cited 2016 June 6]. Available from: http://triblive.com/business/headlines/5709566-74/ industry-jobs-gas

[26] Osborn S, Kleiner BH. Discrimination in the oil industry. Equal Opportunities International 2005;24(3/4):17-26.

[27] Renders, A. Mining industry blind to its homophobic culture: Experts say companies need to step into the 21st century and take LGBT worker issues seriously. Equality at Work 2015;Spring 2015:18-19.

[28] McKee, LE. Women in American energy: De-feminizing poverty in the oil and gas industries. Journal of International Women's Studies 2014;15(1):167-178.

[29] Tallichet SE. Barriers to women's advancement in underground coal mining. Rural Sociology 2000;63(2):234-52.

[30] U.S. Bureau of Labor Statistics. Labor statistics from the Current Population Survey [Internet]. Washington D.C.: U.S. Bureau of Labor Statistics; 2016 [cited 2016 June 7]. Available from: http://www.bls.gov/cps/cpsaat18.htm

[31] IHS Global Inc. Minority and female employment in the oil and gas and petrochemical industries: Prepared for American Petroleum Institute [Internet]. Washington, D.C.: IHS Global Inc.; 2014 [updated 2014 March; cited 2016 July 7]. Available from: http://www.api.org/ /media/ files/policy/jobs/ihs-minority-and-female-employment-rep ort.pdf
[32] McMahon MC, McMahon BT. The National EEOC ADA Research Project: History, available data, and basic findings. Journal of Vocational Rehabilitation 2016;44:333-42.

[33] Van Wieren TA, Armstrong AJ, McMahon BT. Autism spectrum disorders and intellectual disabilities: A comparison of ADA Title I workplace discrimination allegations. Journal of Vocational Rehabilitation 2012;36:159-69.

[34] Van Wieren TA, Reid CA, McMahon BT. Workplace discrimination and autism spectrum disorders: The National EEOC Americans with Disabilities Act Research Project. WORK: Journal of Assessment, Prevention, and Rehabilitation 2008;31:299-308.

[35] Tartaglia A, McMahon BT, West SL, Belongia L, Shier Beach L. Workplace discrimination and healthcare: The national EEOC ADA research project. Journal of Vocational Rehabilitation 2007;27:163-9.

[36] Armstrong AJ, McMahon BT, West SL, Lewis A. Workplace discrimination and cumulative trauma disorders: The National EEOC ADA Research Project. WORK: Journal of Assessment, Prevention, and Rehabilitation 2005;25:49-56.

[37] Unger DD, Rumrill PD, Roessler RT, Stacklin R. A comparative analysis of employment discrimination complaints filed by people with multiple sclerosis and individuals with other disabilities. Journal of Vocational Rehabilitation 2004;20:165-70.

[38] Shaw LR, Chan F, McMahon BT, Kim JH. Employee and employer characteristics associated with elevated risk of filing disability harassment charges. Journal of Vocational Rehabilitation 2012;36:187-97.

[39] Draper WR, Hawley CE, McMahon BT, Reid CA, Barbir LA. ADA perceived disability claims: A decision-tree analysis. Journal of Occupational Rehabilitation 2014;24:213-9.

[40] Grace-Martin K. Can a regression model with a small R-squared be useful? [Internet]. Ithaca, NY: The Analysis Factor; 2012 [cited 2016 May 15]. Available from: http://www.theanalysisfactor.com/small-r-squared/

[41] McMahon BT. An overview of workplace discrimination and disability. Journal of Vocational Rehabilitation 2012;36:135-9.

[42] Chan F, McMahon BT, Cheing G, Rosenthal DA, Bezyak J. Drivers of workplace discrimination against people with disabilities: Physical vs. mental-behavioral genesis. WORK: Journal of Assessment, Prevention, and Rehabilitation 2005;25(1):77-88. 